\title{
Experimental adsorption and desorption characterization of a gasoline-fueled vehicle carbon canister for European application filled with $\mathrm{n}$-butane and nitrogen mixtures
}

\author{
Luca Romagnuolo ${ }^{1, *}$, Marcello Ponticelli ${ }^{1}$, Francesco Fortunato $^{2}$, Vincenzo Mirante ${ }^{2}$, Mario \\ Sammarco $^{2}$, Emma Frosina ${ }^{3}$, Assunta Andreozzi ${ }^{1}$, and Adolfo Senatore ${ }^{1}$ \\ ${ }^{1}$ Department of Industrial Engineering, University of Naples Federico II, via Claudio, 21, 80125 Naples \\ (NA), Italy \\ ${ }^{2}$ Fiat Chrysler Automobiles (FCA), Via Ex Aeroporto, 80038, Pomigliano d'Arco (NA), Italy \\ ${ }^{3}$ Department of Engineering, University of Sannio, Piazza Roma, 21, 82100, Benevento (BN), Italy
}

\begin{abstract}
The evaporative emission control system (EVAP system) is the most commonly used strategy to limit the unburned petrol vapor emissions from a gasoline-fueled vehicle fuel tank, in order to comply with the international regulations on Volatile Organic Compounds (VOCs) emission. A carbon canister is used to collect and store the gasoline vapors generated in the tank, then it is purged by the engine intake manifold depression and the vapors are burned in the engine along with the fresh charge. In this activity, a $1.0 \mathrm{~L}$ carbon canister for European gasoline vehicles, provided by FCA, has been used for an experimental analysis, in order to characterize its adsorption and desorption behavior. A standard mixture of n-butane and nitrogen $(40 \mathrm{~g} / \mathrm{h}$ of n-butane, $50 \%$ vol. with nitrogen) has been used for loading the canister to breakthrough $(2 g)$; canister purging has been performed with 3000 bed volumes of nitrogen flux at $25 \mathrm{~L} / \mathrm{min}$. Tests have been performed in FCA laboratories, at the Pomigliano Technical Center. Canister mass gain has been measured during the tests and after each test with a precision weight scale. Internal temperatures have also been measured by K-type thermocouples placed inside the carbon bed; due to the adsorption process, bed temperatures can reach $70{ }^{\circ} \mathrm{C}$. After several tests, results on mass gain show an "aging" trend of the activated carbons.
\end{abstract}

\section{Introduction}

Unburned hydrocarbon evaporation from a gasoline-fueled vehicle fuel tank has been recognized as an important source of environmental pollution, along with tailpipe emissions. Commercial gasoline is a mixture of over 100 compounds, and many of them can be classified as Volatile and Very Volatile Organic Compounds (VOCs and VVOCs) [1, 2], which can significantly affects human health and environment [3, 4].

Evaporative emissions can be classified by means of their sources: running losses, mainly due to the engine heat and the fuel sloshing in the tank; hot soak losses, after the vehicle is stopped, caused by the engine latent heat; diurnal breathing losses (DBLs), caused by fuel

\footnotetext{
${ }^{*}$ Corresponding author; e-mail: luca.romagnuolo@unina.it
} 
evaporation and expansion in the tank vapor dome, because of solar heat and ambient temperature variations during the day; permeation losses, caused by vapor permeation through the plastic walls of tank and fuel hoses of the entire fuel system; refueling losses, at the service station, when the fresh fuel coming in the tank pushes out the fuel vapor saturated air in the vapor dome. The latter is the biggest source of evaporative emissions, because in few seconds a great amount of fuel vapor is coming out from the vehicle fuel system and also fuel sloshing contributes to produce fuel vapor. To deal with this problem, two main techniques have been developed: the ORVR, mainly used in North America, and the Stage II, adopted in Europe.

Several countries began to adopt regulations that limit the maximum amount of evaporative emissions from gasoline and, later, hybrid vehicles. First regulations were imposed in the USA in the 1970s, from California Air Resources Board (CARB) and the Environmental Protection Agency (EPA) [5, 6]. Many countries of the European Union adopted the UN regulation n. 83 [7] since 1989, which evolved in the current UNECE GTR-19 [8], and also the European emission standards impose stringent limits on the amount of DBLs that can be released into the environment during a certain amount of time (the last stage, Euro 6d imposes a limit of $2.0 \mathrm{~g}$ of fuel vapors during $48 \mathrm{~h}$ of diurnal evaporative emission test).

To deal with these regulations, almost all the gasoline-fueled vehicles are equipped with an evaporative emission control system (EVAP system). A standard EVAP system consists in a carbon canister filter, filled with activated carbons that can adsorb and store fuel vapors coming from the fuel tank, which needs to be connected to the environment in order to avoid unacceptable pressure variations. During driving conditions, the canister is put in communication with the engine intake manifold by a solenoid valve (Purge Control Valve, PCV) and it is purged by clean air from the environment because of depression generated during the engine intake phase. In some conditions, the purged vapors can significantly change the fuel air ratio (up to $15 \%$ ). Therefore, the PCV is not always open during engine on conditions, but its functioning is regulated by the ECU, according to predetermined purging control strategies.

The most effective solution for an EVAP system is to seal the fuel tank to avoid evaporative emissions dispersion in the environment. However, this solution is not common because it requires the tank to be designed to resist to pressure variations that can easily reach 300 mbar. Furthermore, the system should be equipped with a relief valve to open the system before the pressure reaches dangerous levels, and thus it also needs to be equipped with a storage system for the vapor released during this operation, like a carbon canister. This type of system is disadvantageous in terms of complexity, cost and weight and it is adopted only in particular cases, like hybrid vehicles.

Of course, the carbon canister storage is limited by the quantity of activated carbons that are present in it as well as the type of carbons. If a gasoline vehicle is parked for a long time, the canister can easily reach the saturation [9] and then all the fuel vapors coming from the tank are released in the atmosphere. Since this is a serious problem for environmental pollution, through the years several studies have been conducted on adsorption phenomenon [10-15] and, in particular, its application on vehicle canisters [16-19], with the aim to find better solutions, raw materials and treatments to increase canister performance, as well as to develop better purging strategies in order to avoid frequent canister saturation.

In this activity, a 1.0 L carbon canister filter for European applications has been experimentally tested to study its behavior during loading and purging phases, by measuring the dynamic hydrocarbons stored quantity when it is filled and purged with standard n-butane and nitrogen mixture fluxes. Since adsorption and desorption are respectively exothermic and endothermic processes, several thermocouples have been installed inside the carbon bed and outside the canister plastic wall to measure temperature variations during time: temperature data allow to better understand these processes inside the canister, which would otherwise be a closed box. After several loading and purging cycles, it is possible to observe a de- 
crease in canister performance, which is a symptom of the canister "aging". The activity was performed in FCA Pomigliano Technical Center laboratories and the canister tested is a commercial canister used by the group.

\section{Canister properties}

A carbon canister is essentially a plastic box filled with activated carbons; their preparation usually involves two steps: the carbonization of carbonaceous raw material (by pyrolysis) at temperatures below $800^{\circ} \mathrm{C}$ and the activation (or oxidation) made by exposing the carbonized material to an oxidizing atmosphere at high temperatures. This process gives to carbonaceous material a very high interparticle surface area (which can reach $2500 \mathrm{~m}^{2} / \mathrm{g}$ ) and a highly developed porous structure [20]. Activated carbons performance is strongly dependent on the raw material and the activation process, as well as the internal pore distribution. Pores can be classified according to their dimensions: macropores (radii that exceed $50 \mathrm{~nm}$ ), micropores (radii that does not exceed $2.0 \mathrm{~nm}$ ) and mesopores (intermediate dimensions) [21]. Most of the adsorption occurs in micropores and a small amount in mesopores, while macropores only act as ducts for hydrocarbon molecules.

Adsorption is an exothermic process in which a component in its fluid phase (adsorbate) is attracted on the surface of a solid material (adsorbent). This process is highly dependent on adsorbent and adsorbate temperature conditions, and in general, adsorption performances decrease with increasing temperature; therefore, the process intrinsically decreases its performance. Activated carbons adsorption capacity is strongly dependent on the overall surface area since the phenomenon is mainly due to unbalanced molecular forces on solid surfaces. The adsorption can be classified in two types: physical adsorption, in which the adsorbate is bound to the adsorbent surface by relatively weak Van der Walls forces; chemisorption, which involves electrons exchange or sharing between adsorbate and adsorbent molecules, generating a much stronger bond than the previous one. This phenomenon is of a great interest in pollution treatment, and activated carbons have several applications other than vehicle fuel vapor storage [22]; therefore many studies have been developed theoretical and empirical adsorption models [23] .

A carbon canister performance parameter is the butane working capacity (BWC), which is the quantity of n-butane a canister can adsorb before it is saturated. According to GTR-19 [8], the BWC shall be determined by loading the canister with $40 \mathrm{~g} / \mathrm{h}$ of $\mathrm{n}$-butane, in mixture with nitrogen at $50 \%$ vol., until the quantity of n-butane that escapes from the canister reaches $2.0 \mathrm{~g}$ ( 2 grams of breakthrough), and then purging it with 300 bed volumes of nitrogen at $25 \mathrm{~L} / \mathrm{min}$. This process needs to be performed after several loading and purging cycles in order to analyze the performance of an aged canister. Canister aging consists of a performance decrease in storing fuel vapors, mainly due to micropores filling with high boiling hydrocarbons, which can remain trapped even after the purging phase and consequently reduce the effective volume of storage available in the pores [24]. This process continues until the canister reaches a certain stabilization in performance, and therefore its BWC can be considered stable and repeatable. A similar analysis can be performed for determining the gasoline working capacity (GWC), by using specific gasoline fuel vapors instead of n-butane.

\section{Experimental setup}

A U-shape carbon canister filled with $1.0 \mathrm{~L}$ of BAX 1100 wood-based pellets, provided by FCA and specific for European applications (not suitable for ORVR systems), has been the subject of this analysis. The canister has a built-in liquid separator for preventing the liquid 


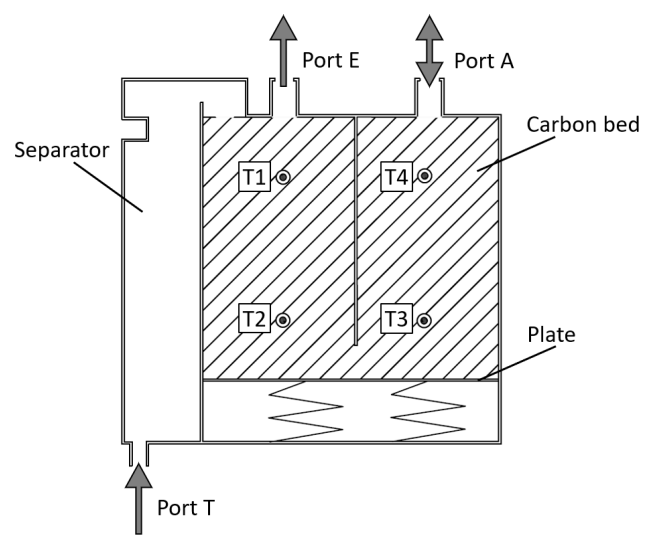

Figure 1: Carbon canister.

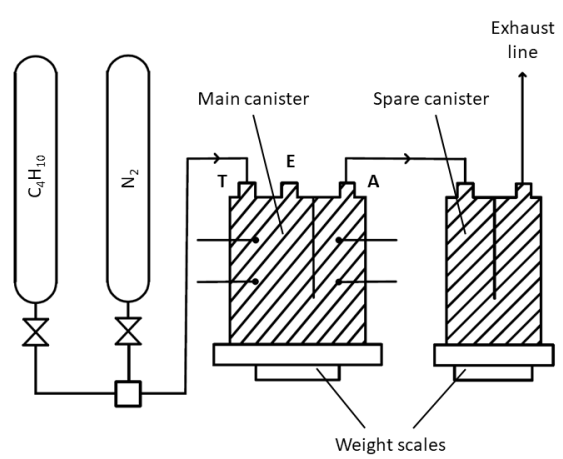

(a)

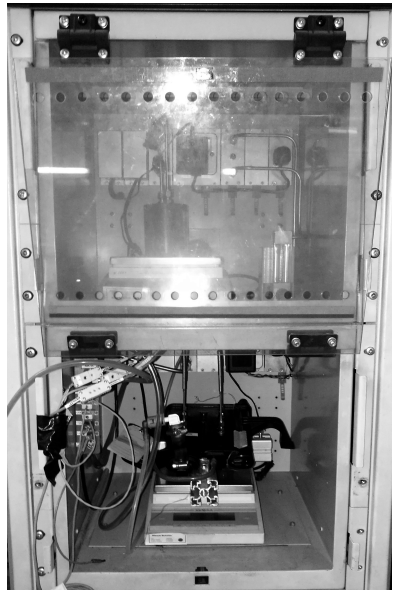

Figure 2: Test bench.

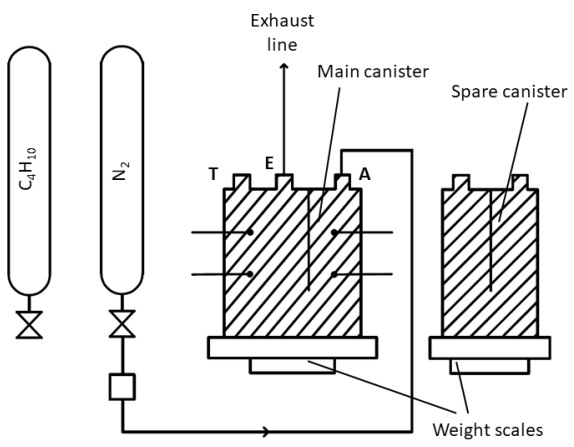

(b)

Figure 3: Test bench setup: (a) loading test and (b) purging test.

fuel to go inside the carbon chamber (this would cause a drastic collapse of the adsorption and desorption performance of the activated carbons) and an internal plate supported by springs, which keeps the activated carbon pellets compressed (fig. 1). During the loading phase, vapor flow coming from the fuel tank (port T) passes through the separator and then through the "U" path, in which fuel vapor is adsorbed from the activated carbons and clean air exits in the atmosphere (port A). During the purging phase, air coming from atmosphere (port A) purges the carbons before being sucked in the engine intake manifold (port E).

Four K-type thermocouples have been installed inside the carbon bed, two of them in each chamber, respectively at $70 \mathrm{~mm}$ and $140 \mathrm{~mm}$ from the topmost section of the canister. Another thermocouple has been placed on the external plastic wall, corresponding to T1 position (thermocouples order follows the loading path). During the experimental activity, several leakage tests have been performed to ensure the canister watertight after the installation of the thermocouples. Canister is then positioned on a metallic support for better stability and ease of installation on the test bench. 
Loading and purging tests have been conducted on a test bench designed for this type of applications (fig. 2). The system can provide n-butane and nitrogen at various mixing levels and mass flow. The canister is placed on a precision weight scale (readability: $0.01 \mathrm{~g}$ ), whose signal is dynamically recorded during the test. For the loading test (fig. 3a), port T is connected to the inlet pipe, which provides the loading flux; port $\mathrm{E}$ is closed. Port $\mathrm{A}$ is connected to a cylinder filled with activated carbons (auxiliary canister or spare canister), which is placed on another weight scale: when the system detects an increase of $2.0 \mathrm{~g}$ of the spare canister weight, the main canister is considered saturated and the test is stopped. The spare canister outlet is connected to an exhaust line and remaining vapors (mainly nitrogen) are disposed in order not to create a pressure increase at the canister outlet. For the purging test (fig. 3b), port A is connected to a purge inlet pipe, which provides a constant flux of nitrogen, while port $\mathrm{E}$ is connected to the exhaust line. The test laboratory is provided with several HC detectors which stop the test if they reveal unburned hydrocarbons in the environment.

The two weight scales and the five thermocouples are connected to a data acquisition system, which monitors the test and records the mass and temperature variations, alongside with the environmental temperature, barometric pressure and volumetric flow of nitrogen and n-butane, with a frequency of one value per minute.

Before and after each test, the canister is weighed on a different scale (readability: $0.01 \mathrm{~g}$ ), with a higher accuracy, to have a static measurement of the canister weight gain (loading test) or loss (purging test), without the weight of pipes and thermocouple connections.

After having pre-weighed the canister and positioned inside the test bench, a constant flow of $40 \mathrm{~g} / \mathrm{h}$ of n-butane mixed with nitrogen at $50 \%$ vol. fills the tested canister until $2.0 \mathrm{~g}$ of breakthrough are measured from the auxiliary canister scale; this process lasts from 2.5 to 3 hours. Since adsorption is an exothermal process, at the end of the loading test the internal temperature is higher than the environmental one, therefore, after having performed another weighing, the canister is cooled down for about 2 hours, until thermocouple $n .4$ measures the environmental temperature. Then the saturated canister is purged inside the test bench with 3000 bed volumes of nitrogen at a constant flux of $25 \mathrm{~L} / \mathrm{min}$, which means that, for a $1.0 \mathrm{~L}$ canister, the purging test lasts 2 hours. It has been decided to use a higher level of purging with respect to the standard regulations $(300 \mathrm{BV})$ to better analyze the purging behavior and the canister mass variation during a longer time, since, as shown below, a nitrogen flow of $300 \mathrm{BV}$ only purges about $60 \%$ of the adsorbed n-butane quantity. Finally, the canister is weighed and test results are post-processed. A complete test cycle is about 6 hours long. Test conditions are summarized in table 1.

Table 1: General testing conditions.

\begin{tabular}{llll}
\hline Canister & & \\
\hline $\begin{array}{l}\text { activated carbons type } \\
\text { canister bed volume }\end{array}$ & BAX 1100 & & \\
\hline Loading & & Purging \\
\hline n-butane constant flow & $40 \mathrm{~g} / \mathrm{h}$ & cooling down time & $\sim 1 \mathrm{~h}$ \\
nitrogen vol. flow rate & 0.5 & nitrogen constant flux & $25 \mathrm{~L} / \mathrm{min}$ \\
initial temperature & $20{ }^{\circ} \mathrm{C}$ & purging flow volume & $3000 \mathrm{BV}(3000 \mathrm{~L})$ \\
environmental temperature & $20^{\circ} \mathrm{C}$ & & \\
\hline
\end{tabular}




\section{Results}

An example of data acquired during a loading test is shown in fig. 4a, which represents the canister mass variation due to n-butane adsorption during time ${ }^{1}$. The plot shows a linear increment of the canister mass for almost $2.5 \mathrm{~h}$, then the curve slope slightly decreases until the test is interrupted at $2.75 \mathrm{~h}$, when the spare canister has loaded at least $2.0 \mathrm{~g}$ of n-butane and the main canister is considered saturated. In fig. $4 \mathrm{~b}$ internal temperatures, recorded from T1 to T4 (see fig. 1 for thermocouples position), are compared each other and with environmental temperature, during time. Since adsorption is an exothermal process, when the carbon bed near the thermocouple begins to adsorb fuel vapor temperature increases rapidly, as seen in T1 and T2, then, it slowly decreases till environmental values. The internal temperature variation allows to follow the adsorption path in the canister bed, while the canister mass gain only gives a total amount of adsorbed hydrocarbons during time. In particular, the shape of the temperature curve suggests that the carbon bed section near the thermocouple rapidly adsorbs a certain amount of fuel vapor and releases energy, then the adsorption rate dramatically decreases and the carbon bed begins to cool down because of thermal exchange with the environment. Moreover, the temperature rise delay between thermocouples shows that each carbon bed section begins the adsorption only when the previous one has completed its first adsorption phase. This is due to a slow diffusion of the fuel vapor through the carbon bed and to the very low n-butane flow rate at the inlet (port $\mathrm{T}$ ). Temperatures recorded from thermocouples 3 and 4 are slightly different from the first ones: there is a small increment of temperature after 1 hour, and before the higher increment that characterizes the beginning of the adsorption. This behavior is due to the thermal exchange between the two canister sections: since $\mathrm{T} 3$ and $\mathrm{T} 4$ are at the same height of $\mathrm{T} 2$ and $\mathrm{T} 1$ respectively, they also record the temperature increase of the left side of the canister.

Results of the purging test are shown in fig. 5a and 5b. Unlike the loading, during the purging test most of the fuel vapor is desorbed in the first minutes of the test, and $90 \%$ of n-butane is purged in less than an hour. After 2 hours, canister mass trend is almost constant, and the canister can be considered purged. The dot on the curve in fig. 5a represents the quantity of desorbed vapor after $300 \mathrm{BV}$ of purging flux, that means after 12 minutes of purging. As we can see in fig. 5b, temperatures recorded from the four thermocouples decrease almost at the same time, showing a different behavior with respect to loading phase: when the fuel vapor is adsorbed, its quantity in the vapor flux is reduced, therefore the next section of the carbon bed is not interested in adsorption until the previous one begins to be saturated; on the other hand the purging flux affects all the sections of the carbon bed at once, therefore the desorption effects are recorded from all the thermocouples at the same time. Then, after the cooldown, the temperature rise delay suggests that desorption is gradually completed, starting from the section that is closer to the inlet port of the purging flux (port A). The purging process can also be influenced by a re-adsorption of butane, which has been purged from the first sections (e.g. near T4) and adsorbed from the last ones (e.g. near T1). This can be detected as a small temperature increase recorded by thermocouples 1 and 2 in the very first minutes of the test.

Temperature recorded by Tskin has been compared with the internal temperature variation recorded by T1, in fig. 6: there is almost no delay between the two peaks, and this can suggest a linear behavior of the adsorption through the carbon bed.

A series of 8 loading and purging cycles have been performed on the tested canister, to detect an aging effect on the loading capacity of the canister. In fig. 7 the total adsorbed quantities after the loading test, non-dimensionalized with respect to the value of the first loading,

\footnotetext{
${ }^{1}$ Values are non-dimensionalized with respect to the final mass value, because of agreements with FCA.
} 


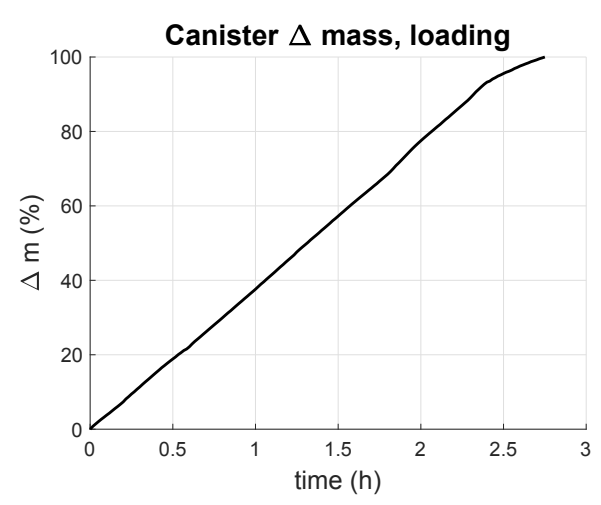

(a)

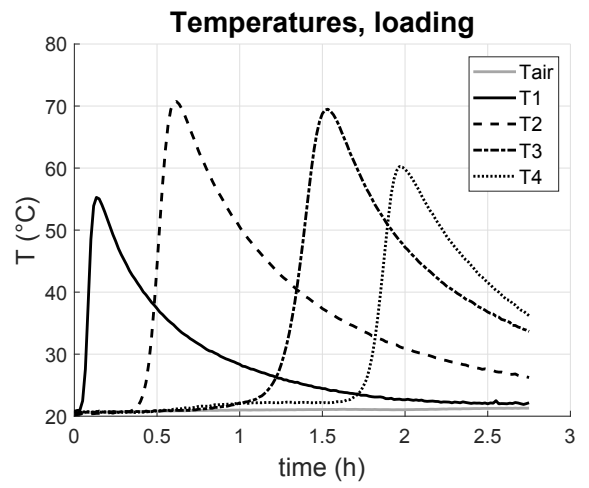

(b)

Figure 4: Canister loading: (a) mass gain and (b) internal temperature variation.

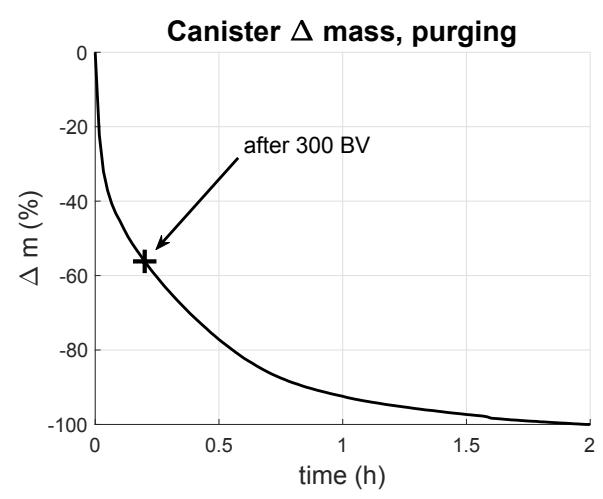

(a)

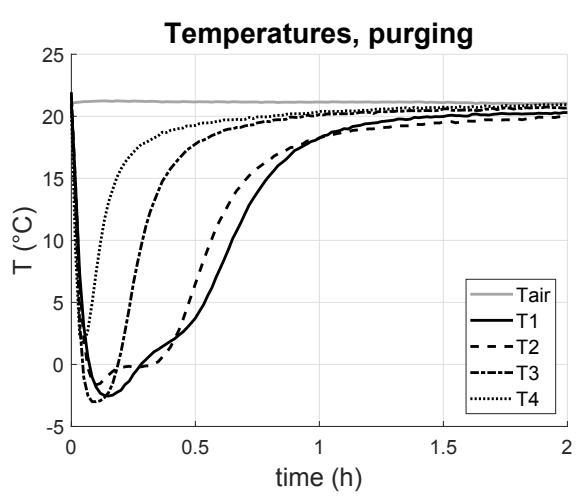

(b)

Figure 5: Canister purging: (a) mass loss and (b) internal temperature variation; dot in (a) represents purging condition after $300 \mathrm{BV}$.

are compared to each other, along with the loading test duration (before breakthrough). There is a decreasing trend for both total mass gain and test time, as expected.

\section{Conclusions}

A 1.0 L carbon canister for European applications, provided by FCA, has been tested in loading and purging with a standard flow mixture of n-butane and nitrogen. Adsorbed and desorbed n-butane quantity has been dynamically measured during the tests by a precision weight scale. Four K-type thermocouples have been installed inside the canister carbon bed and another thermocouple, called skin thermocouple, has been placed on its plastic wall (in correspondence of the first internal thermocouple): internal and skin temperatures have been recorded during the tests, along with environmental temperature. Loading test lasts until a nbutane breakthrough of $2.0 \mathrm{~g}$ is recorded, by monitoring the weight variation of cylinder filled 


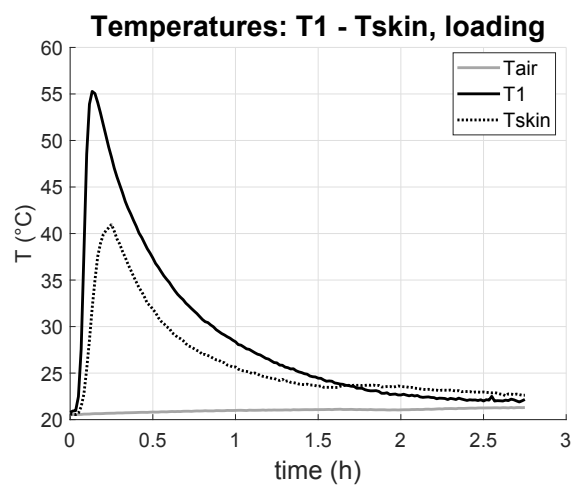

(a)

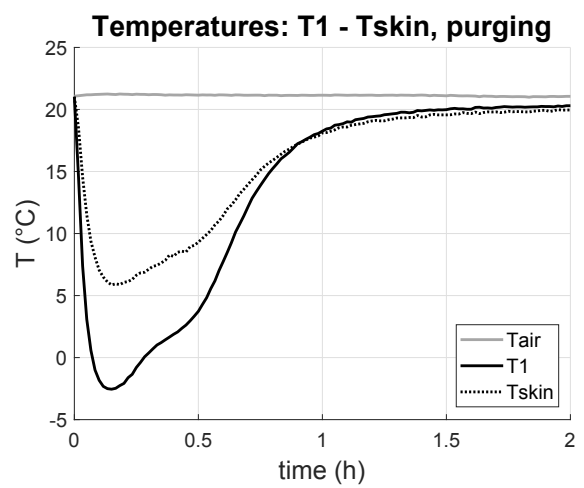

(b)

Figure 6: Internal and skin temperature comparison: (a) loading and (b) purging.

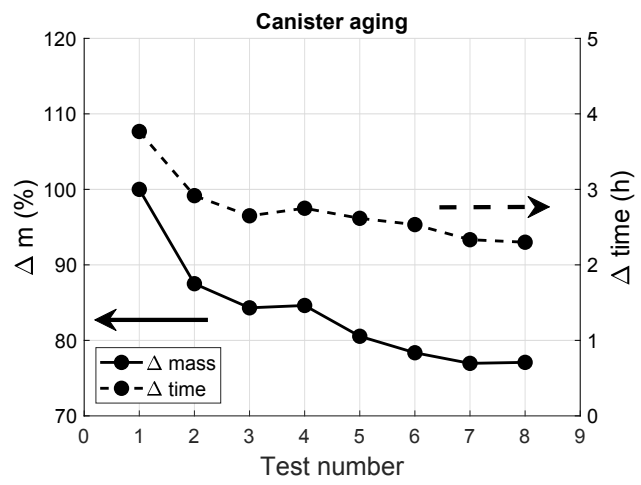

Figure 7: Canister aging: total mass gain after canister breakthrough (non-dimensionalized with respect to the first value) and total loading time.

with activated carbons (auxiliary canister) connected with the output of the tested canister. After a cooldown, canister is purged by a constant flow of nitrogen. The whole test cycle is about $6 h$ long. Several loading and purging cycles have been performed with these conditions on the same canister.

It has been shown that internal temperature recording is an important step for a deeper characterization of the adsorption and desorption behavior of the carbon canister. In fact, with this information, it has been possible to follow the adsorption and desorption "path" inside the carbon bed. In particular the following information can be deduced: for a specific carbon bed section, the adsorption happens in two steps, the first that releases more energy than the second; across the carbon bed, adsorption shows a stratified behavior, the bed filled per layers; during desorption, part of the fuel vapor purged from the first sections of the carbon bed invested by the nitrogen flux can be re-adsorbed from the next sections, determining a small temperature increase.

Mass gain data, recorded from each test, have then been compared each other to find a principle of canister "aging" behavior. It has been seen that after 8 loading and purging 
cycles the carbon canister capacity decreased by more than $20 \%$. However, this reduction is not linear, and looking at the results of the last 3 tests it is possible to see an asymptotical trend of the canister saturation, as common for this type of filters.

This experimental analysis allows to better understand the phenomena that occur inside a carbon canister filter and helps to characterize its storage capabilities and limits. Data can also be used to improve purging performances during driving conditions. Furthermore, this analysis is part of a larger activity that involves FCA and University of Naples Federico II in developing and testing a canister adsorption predictive model.

\section{References}

[1] U.S. Environmental Protection Agency, Technical overview of volatile organic compounds, https://www.epa.gov/indoor-air-quality-iaq/ technical-overview-volatile-organic-compounds

[2] U.S. Environmental Protection Agency, Hydrocarbon composition of gasoline vapor emissions from enclosed fuel tanks (2011)

[3] NIH, Volatile organic compounds, https://toxtown.nlm.nih.gov/ chemicals-and-contaminants/volatile-organic-compounds-vocs

[4] O. Ismail, R. Hameed, Adv. Appl. Sci. Res. 4, 264 (2013)

[5] MECA, Evaporative emission control technologies for gasoline powered vehicles (2010)

[6] U.S. Environmental Protection Agency, Evaporative HC emissions for MOBILE3 (1984)

[7] UNECE, Regulation n. 83: Uniform provisions concerning the approval of vehicles with regard to the emission of pollutants according to engine fuel requirements, https: //www . unece. org/?id=39145

[8] UNECE, Global Technical Regulation No. 19 (EVAPorative emission test procedure for the Worldwide harmonized Light vehicle Test Procedure (WLTP EVAP)), http: //www . unece.org/trans/main/wp29/wp29wgs/wp29gen/wp29glob_registry.html

[9] G. Martini, E. Paffumi, M. De Gennaro, G. Mellios, Science of The Total Environment 487, 506 (2014)

[10] W.K. Lewis, E.R. Gilliland, B. Chertow, W.P. Cadogan, Industrial \& Engineering Chemistry 42, 1319 (1950)

[11] E. Costa, J.L. Sotelo, G. Calleja, C. Marrón, AIChE Journal 27, 5 (1981)

[12] R.J. Wilson, R.P. Danner, Journal of Chemical \& Engineering Data 28, 14 (1983)

[13] I. Langmuir, Journal of the American Chemical Society 38, 2221 (1916)

[14] S. Suwanayuen, R.P. Danner, AIChE Journal 26, 68 (1980)

[15] M.M. Dubinin, V.A. Astakhov, Bulletin of the Academy of Sciences of the USSR, Division of chemical science 20, 3 (1971)

[16] G.A. Lavoie, P.J. Johnson, J.F. Hood, Carbon Canister Modeling for Evaporative Emissions: Adsorption and Thermal Effects, in International Fuels $\mathcal{E}$ Lubricants Meeting $\mathcal{E}$ Exposition (SAE International, 1996)

[17] P.J. Johnson, J.R. Jamrog, G.A. Lavoie, Activated Carbon Canister Performance During Diurnal Cycles: An Experimental and Modeling Evaluation, in International Fuels $\mathcal{E}$ Lubricants Meeting $\mathcal{E}$ Exposition (SAE International, 1997)

[18] K. Sato, K. Yamazaki, N. Kobayashi, Journal of Society of Automotive Engineers of Japan 40, 1327 (2009) 
[19] H. Hata, H. Yamada, K. Yanai, M. Kugata, G. Noumura, K. Tonokura, Science of The Total Environment 675, 679 (2019)

[20] R. Bansal, M. Goyal, Activated Carbon Adsorption (CRC Press, 2005)

[21] IUPAC, Manual of symbols and terminology for physicochemical quantities and units, appendix 2, part $i$ (1971)

[22] K. Foo, B. Hameed, Chemical Engineering Journal 156, 2 (2010)

[23] L. Romagnuolo, R. Yang, E. Frosina, G. Rizzoni, A. Andreozzi, A. Senatore, Renewable and Sustainable Energy Reviews 116 (2019)

[24] H. Itakura, N. Kato, T. Kohama, Y. Hyoudou, T. Murai, Studies on Carbon Canester to Satisfy LEVII EVAP Regulations, in SAE 2000 World Congress (SAE International, 2000), ISSN 0148-7191 